\title{
EVALUATION OF HEMOSTATIC EFFECTIVENESS OF INFUSIBLE PLATELET MEMBRANE IN RABBITS AS A POTENTIAL SUBSTITUTE FOR PLATELET TRANSFUSION
}

\author{
Saleh Nasiri*1 ${ }^{1}$, Majid Heidari ${ }^{1}$ and Saeid Rivandi ${ }^{2}$ \\ ${ }^{1}$ Blood Transfusion Research Center, High Institute for Research and Education in Transfusion Medicine, Tehran, Iran \\ ${ }^{2}$ Iranian Blood Research and Fractionation Company, Quality Control Department, Tehran, Iran \\ *Corresponding author E-mail: salehnasiri2012@gmail.com, Phone: +98-218-860-1501-30, Fax: +98-218-860-1555
}

Received 13 Aug 2012; Review Completed 04 Sep 2012; Accepted 04 Sep 2012, Available online 15 Sep 2012

\begin{abstract}
Several platelet substitutes have been used for transfusion in human and animal models. The potential hemostatic effect of infusible platelet membrane (IPM) was investigated for evaluation its ability to reduce the prolonged bleeding time in thrombocytopenic rabbits. IPM was prepared from outdated platelet concentrates. Platelet concentrates were pooled, disrupted by freeze-thaw procedure, pasteurized for 20 hours to inactivate possible viral or bacterial contaminants. Rabbits were made thrombocytopenic by subcutaneous injection of busulfan dissolved in polyethylene glycol 400. Administration of IPM at a dose of $2 \mathrm{mg}$ per $\mathrm{kg}$ results considerable reduction in the bleeding time. The values of bleeding time in the 48 data sets were obtained. Decrease in the percentage of bleeding time elevation during 2, 4, 6 and 24 hours after injection in the test group of rabbits were found 24.8, 39.0, 52.4 and 95.6 respectively. Reduction in the bleeding time seen in our experimental animals may support clinical potential utility of IPM as a substitute for platelets in the treatment of thrombocytopenia in humans.

Keywords: Infusible platelet membrane, Platelet substitute, Bleeding time.
\end{abstract}

\section{INTRODUCTION}

Platelet transfusion is an effective therapy to control bleeding in thrombocytopenic patients. Unfortunately, blood platelet units are generally stored in blood banks for 3-5 days, thereafter they are discarded ${ }^{1-2}$. For preserving platelets for a long period, a number of attempts have been taken to develop substitutes for platelets, as possible alternatives to currently available platelet concentrates. A number of studies have shown that platelet preparations with impaired metabolic or functional integrity still retain a certain degree of hemostatic property ${ }^{3-6}$. Infusible platelet membrane (IPM) prepared from outdated human platelets have been developed as an alternative to standard platelet concentrates, with the additional advantage of long shelf life and increased viral safety and have confirmed useful in shortening bleeding time in rabbits with experimentally induced thrombocytopenia ${ }^{7}$.

Platelet microparticles are microvesicles of platelet membranes that form during the activation or mechanical disruption of platelets ${ }^{8}$. They form spontaneously during platelet storage and can be detected in platelet concentrates $^{9-11}$, fresh frozen plasma and cryoprecipitate ${ }^{12}$. They have properties of procoagulant activity ${ }^{13}$. Due to these microparticles have similar hemostatic properties as intact platelets, they can be considered as a strategy for the development of a platelet substitute. However, the earliest efforts of these preparations were not successful in vivo and produced considerable distress in experimental animals ${ }^{14}$. With regard to this problem, The investigations postponed for nearly three decades until experiments in thrombocytopenic rabbits provided preclinical evidence of their hemostatic efficacy without significant morbidity ${ }^{15}$. IPMs consist of spherical vesicles with the modal diameter of approximately $0.6 \mu \mathrm{m}$ and are composed of protein and phospholipids similar to that of platelets. IPMs enhance procoagulant activity at sites of vascular injury under conditions of severe and moderate thrombocytopenia ${ }^{16}$. In this study we want to show that IPM has potential clinical use in the treatment of bleeding due to thrombocytopenia.

\section{MATERIALS AND METHODS}

\section{Preparation of IPM}

IPM is prepared from 8 outdated platelet units of Tehran Blood Transfusion Center. The units were pooled and centrifuged for $15 \mathrm{~min}$ at $1000 \mathrm{RPM}$ to remove contaminating red cells and white cells. The supernatant was centrifuged for $30 \mathrm{~min}$ at $2500 \mathrm{RPM}$ to remove plasma. The precipitate was resuspended in $25 \mathrm{ml}$ physiological saline solution (0.9 g\%). For lysis and disruption of platelets, freeze-thaw procedure was repeated three times at $-80^{\circ} \mathrm{C}$ and room temperature for 6 and $2 \mathrm{~h}$ respectively. The solution was washed twice with physiological saline solution for removing of intracellular components by centrifugation (30 min at $2500 \mathrm{RPM}$ ). The precipitate was resuspended in $45 \mathrm{ml}$ of the same solution.

\section{Pasteurization of sample}

The sample of IPM with $0.4 \mathrm{M}$ sodium caprylate concentration was prepared and heated at $60^{\circ} \mathrm{C}$ for $20 \mathrm{~h}$ to inactivate possible viral or bacterial contaminants and formulated with sucrose $1 \mathrm{M}$ and human serum albumin $0.1 \%{ }^{17}$.

\section{In vivo haemostasis assay}

The hemostatic activity of IPM was measured by bleeding time assay to correct prolonged bleeding time in thrombocytopenic rabbits. White New Zealand rabbits 3 to $3.3 \mathrm{Kg}$ in weight were made thrombocytopenic by subcutaneous administration of busulfan dissolved in polyethylene glycol 400 (15 mg/kg on Days $0,2,4$ and 6). We measured platelet count and bleeding time on Day 
Nasiri et al

7,9,11. Animals with $50-70 \times 10^{3}$ per $\mu \mathrm{L}$ with prolonged bleeding time ( $\geq 7 \mathrm{~min}$ ) were used in this assay.

For bleeding time assay, a standard device (ITC Surgicut Bleeding time, Fisher Scientific Inc.) was used to provide uniform standardized incision depth in the ear (Incision $\mathrm{D} \times \mathrm{L}: 1.0 \times 5.0 \mathrm{~mm}$ ) with improved test standardization and reproducibility of bleeding time test results. We applied a Whattman filter paper to the flow of blood from the wound. A stopwatch was started immediately and every 30 seconds filter paper was used to draw off the blood. The time from when the incision was made until all bleeding has stopped was called the bleeding time. We determined the preinjection bleeding time in one ear and administrated IPM at a dose of $2 \mathrm{mg}$ per $\mathrm{kg}$ by injection into the marginal vein of the other ear at a rate of $2 \mathrm{~mL}$ per
Journal of Drug Delivery \& Therapeutics; 2012, 2(5), 1-3 minute. The bleeding times was then measured at various times after injection, 2, 4, 6 and 24 hours. All bleeding time assays were performed in duplicate.

\section{RESULTS AND DISCUSSION}

In previous investigations bleeding time has been used to assessment of the hemostatic effectiveness of various agents in the rabbit model $^{18-20}$. In this study, we administered IPM at a dose of $2 \mathrm{mg}$ per $\mathrm{kg}$, to thrombocytopenic rabbits with platelet count of 50 to 70 $\times 10^{3}$ per $\mu \mathrm{L}$, and we performed 48 sets of bleeding time measurements before of biosulfan injection, before and 2 , 4, 6 and 24 hours after IPM injection. The values of bleedingtime in these 48 data sets are summarized in Table 1.

Table 1: Results of bleeding time measurements during before biosulfan injection, before and after IPM injections in rabbits

\begin{tabular}{|c|c|c|c|c|c|c|}
\hline \multirow{2}{*}{$\begin{array}{l}\text { Bleeding* time } \\
\text { (min) }\end{array}$} & \multirow{2}{*}{$\begin{array}{ll}\text { Before } & \text { biosulfan } \\
\text { injection } & \\
\end{array}$} & \multirow{2}{*}{$\begin{array}{ll}\text { Before } & \text { IPM } \\
\text { injection } & \\
\end{array}$} & \multicolumn{4}{|c|}{ Time after IPM injection (hours) } \\
\hline & & & 2 & 4 & 6 & 24 \\
\hline Rabbit No 1 & 2.5 & 7.0 & 1.9 & 3.6 & 4.1 & 6.7 \\
\hline Rabbit No 2 & 2.7 & 7.3 & 1.6 & 2.2 & 3.5 & 7.1 \\
\hline Rabbit No 3 & 2.8 & 7.2 & 1.6 & 2.4 & 4.1 & 6.8 \\
\hline Rabbit No 4 & 3.1 & 10.0 & 2.7 & 4.1 & 4.8 & 9.5 \\
\hline Mean & 2.8 & 7.9 & 2.0 & 3.1 & 4.1 & 7.5 \\
\hline
\end{tabular}

* Bleeding time was performed in duplicate and the mean was calculated

Because all the platelet counts in these animals are much lower than the normal mean value of $430 \times 10^{3}$ per $\mu \mathrm{L}$, the bleeding times were considerably longer than the normal value of 1.7 minutes. In this study for reliability of the results, the bleeding time was measured in duplicate and the mean was calculated.

The 10 sets of percentages of bleeding time elevations, and the corresponding data from 2 administrations of excipient (sucrose and human serum albumin in $0.9 \%$ siodium chloride) to another group of rabbits, are summarized in Fig-1. For comparison of results, we expressed decrease in the percentage of bleeding time elevation after the administration of IPM to thrombocytopenic rabbits (Fig-1). As one can see from top curve in Fig-1, there is no significant change in the bleeding times of animals given excipient used in IPM formulation. Reduction in the percentage of bleeding time elevation during 2, 4, 6 and 24 hours after injection in the test group of rabbits were found 24.8, 39.0, 52.4 and 95.6 respectively (Fig-1).

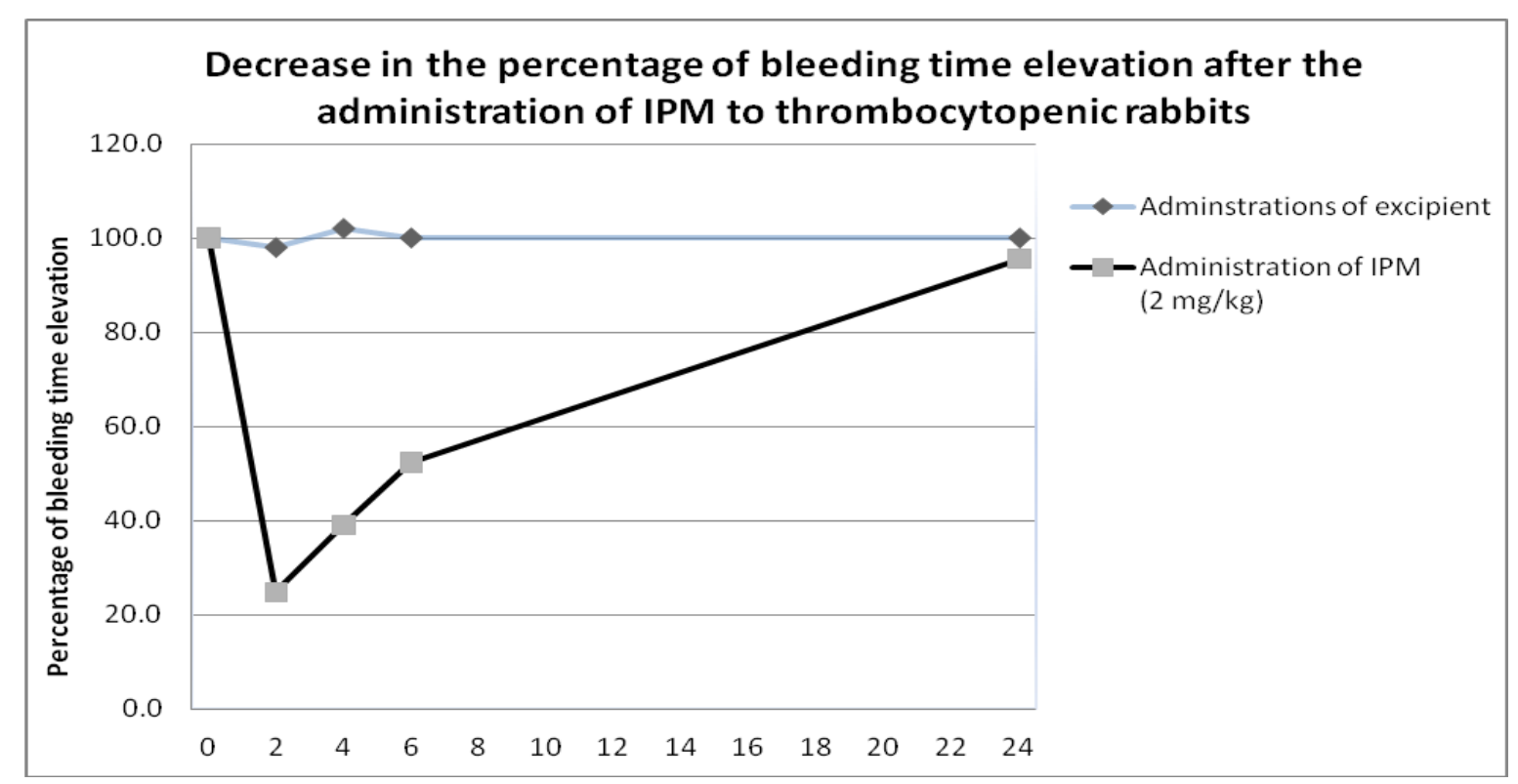

Hours after IPM injection

Fig 1: Decrease in the percentage of bleeding time elevation after the administration of IPM to thrombocytopenic rabbits. The bleeding time was measured to a maximum of 15 minutes after 4 administrations of IPM at a dose of 2 mg per $\mathrm{kg}$ and 2 administrations of excipient (sucrose and human serum albumin in $0.9 \%$ sodium chloride) 


\section{Nasiri et al}

The results of previous study was nearly similar to our study and has shown that administration of IPM (2 mg $/ \mathrm{kg})$ can shorten the prolonged bleeding time in thrombocytopenic rabbits at least $4 \mathrm{~h}$ after infusion ${ }^{7}$; however, in our study the maximum decrease in the percentage of bleeding time was observed at $2 \mathrm{~h}$ after infusion instead of $4 \mathrm{~h}$. In both studies this hemostatic effect was no longer detectable after $24 \mathrm{~h}$ of IPM administrations.

The reduction of bleeding time in experimental animals in our study confirms the potential utility of IPM as a substitute for platelets in the treatment of thrombocytopenia in humans. The clinical utility of the bleeding time in clinical aspects is controversial. Many experts regard the bleeding time as useless, in that it does not predict surgical bleeding. Articles supporting this view are often presented by pathologists. Despite such articles, the bleeding time continues to be used by many clinicians, primarily surgeons ${ }^{21-25}$.
Journal of Drug Delivery \& Therapeutics; 2012, 2(5), 1-3 However, in this research, the bleeding time is used to determine the response in a group of rabbits, almost identical in age and weight, that are relatively healthy, though thrombocytopenic. The main point of this study is the change in the bleeding time during the early hours after the injection of IPM. An acceptable number of animals has been used, and the each assay was performed in duplicate. Our results indicate hemostatic effectiveness of IPM in this experimental setting.

For possible usage of IPM as a drug in human and evaluation of its clinically significant consequences, human clinical trials should be performed in the future.

\section{CONCLUSION}

Reduction in the bleeding time seen in experimental animals may support clinical potential utility of IPM as a substitute for platelets in the treatment of thrombocytopenia in humans.

\section{REFERENCE}

1. Hess JR. Conventional blood banking and blood component storage regulation: opportunities for improvement. Blood Transfusion, 2010, 8(Suppl 3), s9-s15.

2. Blajchman MA, Slichter SJ, Heddle NM, Murphy MF. New strategies for the optimal use of platelet transfusions. Hematology Am Soc Hematol Educ Program, 2008, 198-204.

3. Graham SS, Gonchoroff NJ, Miller JL. Infusible platelet membranes retain partial functionality of the platelet GPIb/IX/V receptor complex. Am J Clin Pathol., 2001, 115(1), 144-7.

4. Hawiger J. Mechanisms involved in platelet vessel wall interaction. Thromb Haemost, 1995, 74, 369-72.

5. B S Coller, K T Springer, J H Beer, N Mohandas, L E Scudder, K J Norton, S M West. Thromboerythrocytes. In vitro studies of a potential autologous, semi-artificial alternative to platelet transfusions. J Clin Invest., 1992, 89(2), 546-555.

6. Read MS, Reddick RL, Bode AP, Bellinger DA, Nichols TC, Taylor K, Smith SV, McMahon DK, Griggs TR, Brinkhous KM. Preservation of hemostatic and structural properties of rehydrated lyophilized platelets: potential for long-term storage of dried platelets for transfusion. Proc Natl Acad Sci U S A., 1995, 92(2), 397-401.

7. Chao FC, Kim BK, Houranieh AM, Liang FH, Konrad MW, Swisher SN, Tullis JL. Infusible platelet membrane microvesicles: a potential transfusion substitute for platelets. Transfusion, 1996, 36(6), 536-42.

8. Owens M. The role of platelet microparticles in haemostasis. Transfusion Medicine Reviews, 1994, 8, 37-44.

9. Solberg C, Holme S, Little C. Morphological changes associated with $\mathrm{pH}$ changes during storage of platelet concentrates in first-generation 3-day container. Vox Sanguinis, 1986, 50, 71-77.

10. George JN, Pickett EB, Heinz R. Platelet membrane microparticles in blood bank fresh frozen plasma and cryoprecipitate. Blood, 1986, 68, 307-309.

11. Bode AP, Orton SM, Frye MJ, Udis, BJ. Vesiculation of platelets during in vitro aging. Blood, 1991, 77, 887-895.

12. George JN, Pickett EB, Heinz R. Platelet membrane microparticles in blood bank fresh frozen plasma and cryoprecipitate. Blood, 1986, 68, 307-309.

13. Owens M.R, Holme S, Cardinali S. Platelet microvesicles adhere to subendothelium and promote adhesion of platelets. Thrombosis Research, 1992, 66, 247-258.

14. Hjort PF, Perman V, Cronkite EP. Fresh, disintegrated platelets in radiation thrombocytopenia: Correction of prothrombin consumption without correction of bleeding. Proceedings of the Society of Experimental Biology and Medicine, 1959, 102, 31-35.

15. McGill M, Fugman DA, Vittorio N, Darrow C. Platelet membrane vesicles reduced microvascular bleeding times in thrombocytopenic rabbits. Journal of Laboratory and Clinical Medicine, 1987, 109, 127-133.

16. Galan AM, Bozzo J, Hernandez MR, Pino M, Reverter JC, Mazzara R, Escolar G, Ordinas, A. Infusible platelet membranes improve haemostasis in thrombocytopenic blood: experimental studies under flow conditions. Transfusion, 2000, 40, 1074-1080.

17. Nasiri S, Heidari M. Application of sodium caprylate as a stabilizer during pasteurization of infusible platelet membrane and evaluation of effectiveness by turbidity assay. International Journal of Analytical, Pharmaceutical and Biomedical Sciences, 2012, 1(2), 34-36.

18. Wagner SJ, Bardossy L, Moroff G, Dodd RY, Blajchman MA. Assessment of the hemostatic effectiveness of human platelets treated with aminomethyltrimethyl psoralen and UVA light using a rabbit ear bleeding time technique. Blood, 1993, 82, 3489-3492

19. Levi M, Friederich PW, Middleton S, de Groot PG, Wu YP, Harris R, Biemond BJ, Heijnen HF, Levin J, ten Cate JW. Fibrinogen-coated albumin microcapsules reduce bleeding in severely thrombocytopenic rabbits. Nat Med., 1999, 5(1), 107-11.

20. Wong PC, Crain EJ, Watson CA, Jiang X, Hua J, Bostwick JS, Ogletree ML, Schumacher WA, Rehfuss R. Platelet aggregometry and receptor binding to predict the magnitude of antithrombotic and bleeding time effects of clopidogrel in rabbits. J Cardiovasc Pharmacol., 2007, 49(5), 316-24.

21. Lind SE. Prolonged bleeding time. Am J Med. 1984, 77(2), 305-12.

22. Rodgers RP, Levin J. A critical reappraisal of the bleeding time. Semin Thromb Hemost., 1990, 16(1), 1-20.

23. Lind SE. The bleeding time does not predict surgical bleeding. Blood, 1991, 77(12), 2547-52.

24. Peterson P, Hayes TE, Arkin CF, Bovill EG, Fairweather RB, Rock WA, Triplet DA, Brandt JT. The preoperative bleeding time test lacks clinical benefit [Review]. Arch Surg, 1998, 133, 134-139.

25. Lehman CM, Blaylock RC, Alexander DP, Rodgers GM. Discontinuation of the bleeding time test without detectable adverse clinical impact. Clin Chem., 2001, 47(7), 1204-11. 